\title{
Analysis of Heavy Metals in Lipstick by the Various Physio- Chemical and Instrumental Methods
}

\author{
*Roopa S Belurkar ${ }^{1}$ and Mallikarjun S Yadawe ${ }^{2}$ \\ Parvatibai Science college Goa ${ }^{l}$ \\ S.B.Arts and K.C.P.Science College Bijapur ${ }^{2}$, Karnataka India
}

\begin{abstract}
The study was aimed at assessing the levels of some toxic metals in different Lipstick products sold at different shopping malls and markets in Goa Metropolis. The cosmetic items included eighteen lipsticks of various prices. The lipsticks were digested and analyzed for heavy metals ( lead, cadmium and Nickel) using atomic absorption spectrophotometer.It is obvious from the present study that the use of these lipsticks exposes users to low concentrations of toxic heavy metals which could constitute potential health risk to users since they are known to accumulate in biological systems over time. Similarly, regular monitoring of other heavy metals and chemicals used in the manufacture of lipsticks products which may cause health risks to users should be emphasized.
\end{abstract}

\section{Introduction}

Cosmetic is defined as "Any article intended to be rubbed, poured, sprinkled or sprayed on, or introduced into, or otherwise applied to, the human body or any part thereof for cleansing, beautifying, promoting attractiveness, or altering the appearance, and includes any article intended for use as a component of cosmetic[1] . Cosmetic products are regulated for health and safety. There are concerns regarding the presence of harmful chemicals, including heavy metals, in these products. There has not been many studies on presence of heavy metals in cosmetics in India. To assess the levels of heavy metals, PML conducted a study on commonly available lipsticks, fairness creams, lip balms and antiaging creams. A cosmetic is a substance or preparation used in contact with various parts of the human body such as epidermis, hair, nails, lips and external genital organs (external parts) or applied to the teeth or mucous membranes of the oral cavity with a view or for the purpose of cleaning, perfuming, protection, changing their outlook, converting body odours and keeping the surfaces in good condition [2,3]. Cosmetics are mixtures of some ingredients such as surfactants, oils and they need to be effective, long lasting, stable and safe to human use [4]. Use of cosmetic products is increasing rapidly in India and various chemicals including the heavy metals are used in the cosmetics which pose health risk to consumers. The present study was conducted to determine heavy metals - lead, cadmium, chromium and nickel in lipsticks, lip-balm and anti-ageing creams and mercury in fairness creams available in the Delhi market. The results were compared with the available standards. A large number of heavy metals are present in lipsticks.Some of these are used as coloring agent. Some of these metals are added as intentionally ingredients while some added accidently from environment.Skin care products fall in general category of cosmetics. These are used to improve the appearance and health of skin. Skin function as protective layer [5]. It allows some chemical substances to pass through it, while it does not allows some chemical substances to pass. Some cosmetics products are directly applied to the skin such as lipsticks. These enter into the body and cause the hazardous effect to the internal body organs.Cosmetics are the important source of releasing heavy metals in the environment.

Cosmetics represent an important source of sensitization, since they are used every day and are applied to the thinnest areas of facial skin, such as thepreocular areas and lips, where absorption is very high [6].Lead in the earth crust is naturally present, its atomic number is 82 , atomic weight is 207.19 , its specific gravity is 11.34 ,it is silvery grey or bluish metal it have at atmospheric pressure boiling point is $1740^{\circ} \mathrm{C}$ and melting point $327.5^{\circ} \mathrm{C}$ [7]. From 2000 years lead poisoning has been known that have dangerous effects on human health. Main human problems that occurred due to lead toxicity are stomach pain, unconsciousness, anemia, infertility, nervous systems disorders. Its low level introduction into the body causes behavior abnormalities, learning and hearing disorders. Lead effects on the every systems of the body such as reproductive system, renal system, hepatic etc.[8]. In the brain lead in toxic amount alter the nerve transmission and slow down the calcium transport in the human body. During pregnancy lead can cross the placenta and causes the premature delivery, and low birth weight. Lipstick can become contaminated with lead via the use of contaminated raw materials or via the use of pigments that contain lead. The level of lead was less than $20 \mathrm{ppm}$ in all products in a study on its presence in 88 different colours of eye shadow [9]. Cadmium is present in many cosmetics products but mostly present in lipsticks and face powders. Its color is deep yellow to orange. It is used as color pigment in many cosmetics industries. Cadmium absorption through the skin is very low (0.5\%). It binds to epidermal keratin thus limited 
absorption observed through in vitro. Oral limited value for cadmium is $0.09 \mu \mathrm{g} / \mathrm{kg}$ to $3 \mathrm{ppm}$ is given by USP for nutritional supplements. The threshold value for dietary products exposure is below $2.5 \mu \mathrm{g} / \mathrm{kg}$ per body weight in a week. Cardiovascular system is also affected at the low level of cadmium exposure. Diabetes and hypertension are also associated with its exposure [10].

The aim of this survey was to assess the public Health risk from certain brands of lipsticks products sold at Goa region. A total of eighteen different samples of lipsticks from different brands were studied for the presence of three heavy metals in them. Besides the presence of heavy metals across different colours of the same brand were also sought to be detected and analyzed.. Our concern arises from the safety of cheap priced lipsticks that is sold widely in stored around Goa region. Most of these products are imported from countries which have weak regulatory inspection and screening as well as no standard conditions for manufacturing.

\section{I.Sampling.}

\section{Materials And Methods}

16 samples from different brands made from different countries were randomly purchased for analysis but a single brand may contain several colors which have been analyzed separately. Besides, the presence of heavy metals across different colours of the same brand were also sought to be detected and analyzed. For this, Lipsticks of the commonly used colours pink, red, brown, purple and maroon shades were chosen for studies. They are very popular and most of them are imported mainly from developing countries where no quality control measures are applied.

\section{Estimation of Lead, Cadmium and Nickel.}

All glassware and plastic containers used were washed with liquid soap, rinsed with water, soaked in $10 \%$ volume/volume nitric acid for $24 \mathrm{hrs}$, cleaned thoroughly with distilled water and dried in such a manner to ensure that any contamination does not occur. Blanks and samples were also processed and analyzed simultaneously. All the chemicals used were of analytical grade (AR). For heavy metal analyses 1 gram of each sample was weighed on electronic balance. The samples were analyzed according to standardized international protocols by wet digestion method, (Using $\mathrm{HNO}_{3}$ and $\mathrm{HClO}_{4}(3: 1)$ and $\mathrm{H}_{2} \mathrm{O}_{2}$ ), analyzed by a Flame Emission Spectrophotometer Model AA-6300 (Shimadzu, Japan) using an air-acetylene flame for heavy metals, using at least five standard solutions for each metal. All necessary precautions were taken to avoid any possible contamination of the sample as per the AOAC guidelines (AOAC, 1998).

FT-IR/ATR spectra were recorded at room temperature using aSymotz 1S spectrometer equipped with ATR detector with the diamond crystal in the $4000-400 \mathrm{~cm}-1$ range. A sample of the tested material was mechanically pressed onto the diamond crystal.

\section{PHYSICO-CHEMICAL METHODS}

\section{Results And Discussion}

The levels of metals found in eighteen brands taken for the studies are given in Table 1.A total of 18 different samples of lipsticks from different brands were studied for the presence of Heavy metals.Besides, the presence of heavy metals across different colours of the same brand were also sought to be detected and analyzed. For this, different brandswere chosen and Lipsticks of the commonly used colours pink, red, brown, purple and maroon shades were chosen for studies.

Table 1:-Results of analysis of different brands of lipsticks

\begin{tabular}{|l|l|l|l|l|}
\hline Sr.No & Same Name & Lead in $\mathrm{mg} / \mathrm{kg}$ & Cadmium $\mathrm{in} \mathrm{mg} / \mathrm{kg}$ & Nickel in $\mathrm{mg} / \mathrm{kg}$ \\
\hline 1 & Miss Gold-17 & 2.5 & 1.40 & 0.24 \\
\hline 2 & Bonsoir-30 & 2.00 & 2.10 & 0.014 \\
\hline 3 & Mars mini & 7.00 & 3.05 & 1.53 \\
\hline 4 & 0.85 & 0.27 & 3.42 \\
\hline 5 & Lipstick-31 & 10.2 & 4.00 & 1.00 \\
\hline 6 & Maybelline & 0.10 & $\mathrm{ND}$ & 5.35 \\
\hline 7 & Corolla-33 & 5.30 & 2.10 & 0.035 \\
\hline 8 & Cover Girl-22 & 3.95 & 1.00 & 0.83 \\
\hline 9 & Coloressence-118 & 1.60 & 0.25 & 6.56 \\
\hline 10 & Personi-308 & 0.40 & 0.43 & 5.94 \\
\hline 11 & Ciannuo-Pink magic lip & 3.55 & 1.65 & 7.86 \\
\hline 12 & Neckline & 1.10 & 0.50 & 0.46 \\
\hline 13 & Liboni-33 & 9.60 & 2.70 & 2.03 \\
\hline 14 & Yaris Lipstick & 0.60 & 0.35 & 0.957 \\
\hline 15 & Passion & 20.15 & 3.04 & 0.30 \\
\hline 16 & Steel Paris & 2.45 & 0.60 & 2.86 \\
\hline 17 & Kiss Beauty & 21.80 & 0.30 & 1.23 \\
\hline 18 & Blue Heaven Purple & 5.20 & 0.95 & 3.4 \\
\hline
\end{tabular}


Lead: Lead was the most commonly detected heavy metal in many brands.Lead content was determined in 18 tested lipstick samples; the highest $\mathrm{Pb}$ content was $21.80 \mathrm{mg} / \mathrm{kg}$ inBlue Heaven Purple and the lowest was $0.40 \mathrm{mg} / \mathrm{kg}$ in Ciannuo-Pink magic lip. This large variation in the concentration of lead may be attributed to the quality of the raw materials used in the production of the lipsticks. The FDA has established $20 \mathrm{mg} / \mathrm{kg}$ as the maximum amount of lead allowed in color additives used to make cosmetics for external use, produced using good manufacturing practices [11].However, there exists no legislation for regulating the level of toxic metals in lipsticks in the US, Europe, Asia or Brazil. Recently, the level of lead in a number of different lipsticks was determined by the US FDA [12]; the highest lead content found was $3.06 \mu \mathrm{g} \mathrm{g}^{-1}$, and the lowest lead content was $0.09 \mu \mathrm{g} \mathrm{g}^{-1}$. In 2007, lead was also found in $61 \%$ of the 33 brands of lipsticks tested by the CSC, with lead levels ranging from 0.03 to 0.65 [13]. Although the lead found in lipsticks is only a minor source of lead exposure when compared to other sources such as water, food and/or air, lead exposure from lipsticks should not be overlooked. Some of the ingredients in lipsticks can penetrate the skin and reach vital internal organs via the systemic circulation. In addition, lipsticks also have a higher risk of direct oral ingestion which may aggravate the negative effects of its chemicals [14].

Metals accumulate in the body over time, and the repetitive application of metal-containing product(s) may lead to significant and dangerous levels of exposure. The effects of toxic lead exposure are well known and include damage to the kidneys and to the central nervous system, memory loss, and other symptoms [15]. the toxicity of lead at high concentrations of exposure is well documented but a major concern in recent time is the possibility that continual exposure to even relatively low levels of these toxic metals in cosmetic products may pose potential health risks [16]. The possibility of skin allergy and contact dermatitis may increase due to the presence of heavy metals in cosmetics. In this study, the different cosmetic products were tested for the presence of arsenic, cadmium, lead, mercury and nickel.

Cadmium: The highest concentration of $4.0 \mathrm{mg} / \mathrm{kg}$ was obtained in Maybelline which is also a local formulation where as the lowest concentration of $0.25 \mathrm{mg} / \mathrm{kg}$ was found in sample Personi-308. Although the presence of cadmium in the samples was in less amount but the slow release of cadmium with low amount may also cause harmful effects to the human body. The presence of cadmium has also reported in various lipsticks it does not have to be present in abundance in products to produce hypertension. The small amount of cadmium is not safe. It targets blood vessel and heart tissue, as well as, the kidneys, lungs and brain, and results in heart disease, hypertension, liver damage, suppressed immune system and other nasty symptoms. National Institute for Occupational Safety and Health (NIOSH) classifies cadmium as a human carcinogen. Cadmium binds to epidermal keratin when applied topically, thus explaining the limited dermal absorption observed in vitro. However, significant dermal exposure, as could occur in an occupational setting, can cause irritant dermatitis [17].

Nickel: The highest concentration of $7.86 \mathrm{mg} / \mathrm{kg}$ in sample Necklinewhile the lowest concentration of $0.014 \mathrm{mg} / \mathrm{kgwas}$ found in sampleBonsoir-30.A number of metals and their compounds may cause adversereactionsuponcontactwiththeskin [18].Although somearetoxic, causing irritantcontactdermatitis, ulceration, or granuloma, the most common effect is contact allergy. Nickel is the most common cause of contact allergy of all skin sensitizers, and it is also an important cause of hand eczema. Sensitization to nickel is generally caused by direct andprolongedskincontactwithitemsthatreleasenickelions. Dependingonfashion,femalesofallergies children,youths, and adults are more exposed to nickel from such items thanmen.Therefore,nickelallergyismuchmorefrequentin women than in men. Approximately 15-20\% of the women and2-5\%ofthemareallergictonickel[19].Itisdifficult to estimate whether a person not previously sensitized to nickelmightacquireanallergyfromtheproductsstudied. In individualssensitizedtothesemetals, concentrationsaslow as1ppmofnickelmaycauseanallergicreaction [20].

IR Spectra: Interpretation of the IR spectra of cosmetic products is complicated due to the fact that each of the functional groups visible on the IR spectrum may be responsible for the appearance of multiple bands in a wide range of wave numbers, so that each band may have a contribution of many functional groups. Additionally, the presence of substances such as water or paraffin compounds may are also impede the analysis. These paraffin substances are visible in the IR spectrum in the range of $3000-2800 \mathrm{~cm}^{-1}$ (-CH bands) and $1500-1100 \mathrm{~cm}^{-1}$. Water reveals bands within $3600-2800 \mathrm{~cm}^{-1}$ and $1700-1300 \mathrm{~cm}^{-1}$ range, and those bands may overlap with the bands of tested cosmetics and hinder the interpretation of the spectra.

Figure 1-4 shows the FT-IR spectra of analyzed lipstick. In all IR spectra of tested lipstick the absorption bands have the same position, but the greatest similarity can be observed in the photoacoustic and transmissionspectra. Although, there are bands in the 1650-1500 cm-1 range, which are not visible on ATR or DRS spectra. Additionally, the bands at 3212 and $825 \mathrm{~cm}-1$ are present only in the photoacoustic spectrum.Broad band in the range of $3600-3000 \mathrm{~cm}-1$ indicates the presence of intramolecular hydrogen bonds. 
The bands in 3000-2800 cm-1 $(2957,2924,2852 \mathrm{~cm}-1)$ indicate the presence of aliphatic hydrocarbons in the tested cosmetic. The latter may be confirmed analyzing the spectra in the $14601379 \mathrm{~cm}-1$ range (aliphatic $-\mathrm{CH}$ groups). The bands at $\sim 1560$ and $\sim 1370 \mathrm{~cm}-1$ indicate the presence of aromatic compounds. The wide band of $\mathrm{SiO}$ in the $1270-850 \mathrm{~cm}-1$ range indicates the presence of silicates in considered cosmetic product. Obtained IR spectra display multiple bands which correspond to the wavenumbers characteristic for propyl ester of hexanoic acid $\left(1743,1460,1418,1379,1363,1163,1109,1040,723 \mathrm{~cm}^{-1}\right)$ [21].

Fig.1

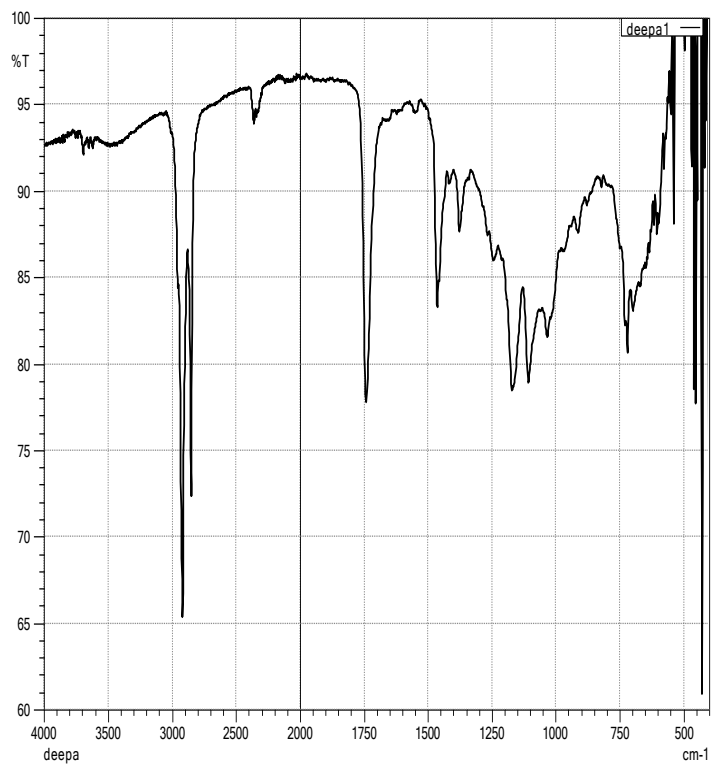

Fig.3

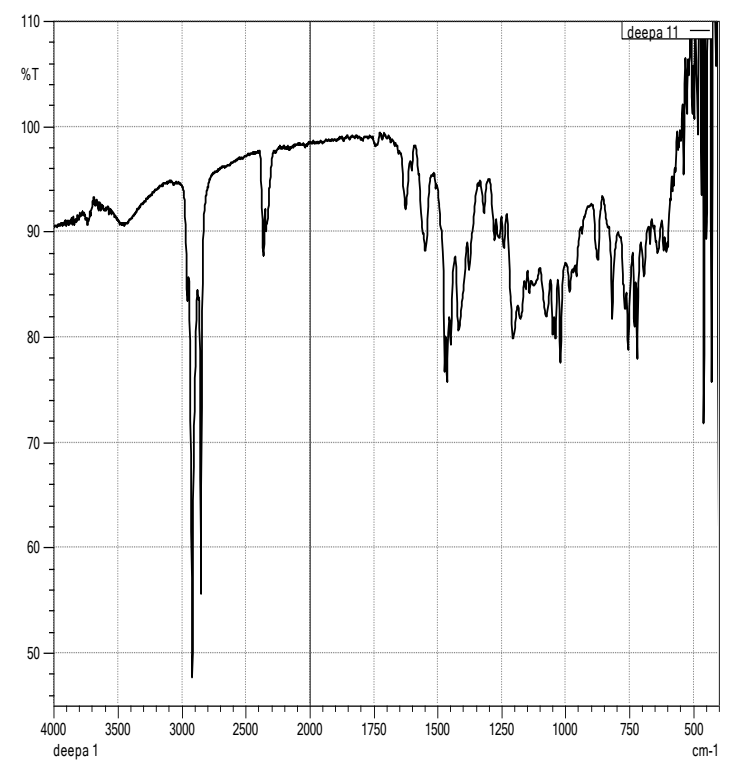

Fig.2

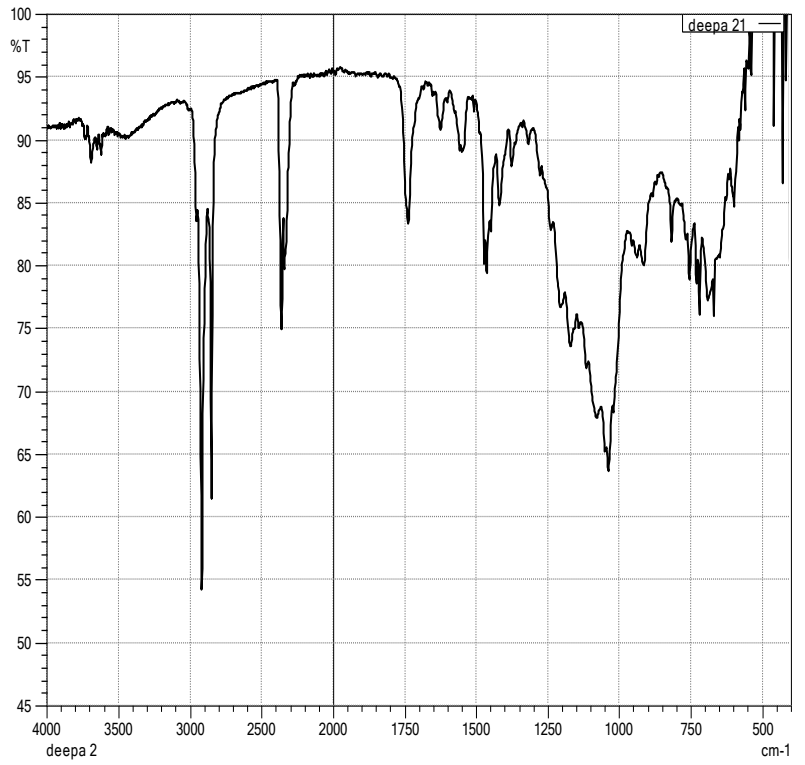

Fig.4

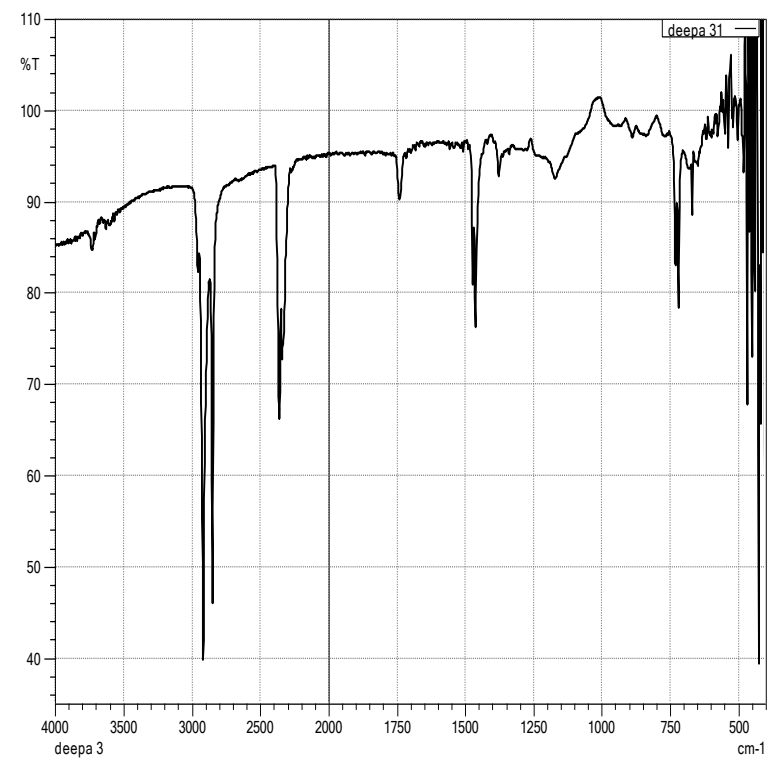

THERMOGRAM OF LIPSTICKS: A broad endothermic peak is observed from $~ 30-90{ }^{\circ} \mathrm{C}$. When this is compared to the melting profiles shown in both Figure 6,it becomes clear that an individual wax will not provide the melting profile required for lipstick application for two reasons. (1) $\mathrm{CW}$ has a high melting point with the majority of wax crystals melting at $\sim 85{ }^{\circ} \mathrm{C}$, this would be unsuitable for lipstick application as wax crystals would have to start to melt at lip temperature $\left(32{ }^{\circ} \mathrm{C}\right)$ and (2) MW is too soft to produce lipstick bullets even though it does have the desired melting profile Therefore a combination of MW and CW was investigated for their possible use as the continuous phase of an emulsion based lipstick.

Fig.6 


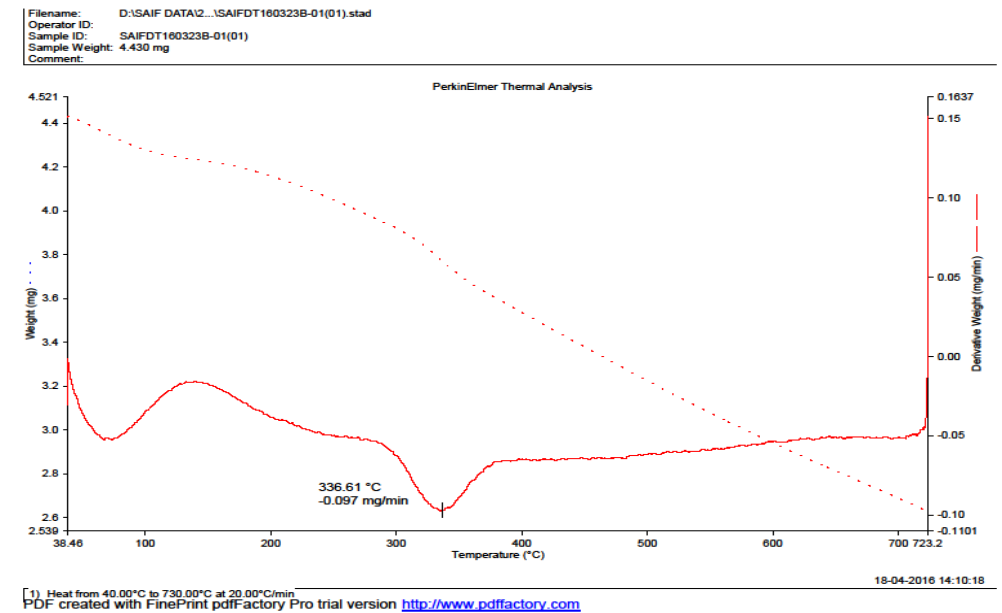

\section{Conclusion}

The probable causes that may be inferred for the presence of these toxic metals can be stated as following:- a) Contamination at the raw materials stage. Use of substandard raw material in order to save the cost, ignorance created by non technical and under skilled manpower for which there exists no regulation. b) Use of improper grade of water. Faculty water system and both. c) Leaching by the container and the machinery employed. d) Lack of skilled Labor. e) Lack of compliance by small scale cosmetic manufacturers. f) Lack of strict regulatory compliance. g) Adverse effect cases due to cosmetics use are under reported and poor documentation which gives a free hand to the manufacturers. h) Pre market testing is not at all mandatory for cosmetics even by FDA. i) Disjointed legislation at the national and international level.

\section{Acknowledgements}

Authors are thankful to Principal, Management of Smt. Parvtibai college of Arts \& Science, Goa, India.

\section{References}

[1]. Drug and Cosmetic Act, 1940 available at http://cdsco.nic.in/html/copy\%20of\%201.\%20d\&cact121.pdf

[2]. F.O.Oyedeji,G.o.Hssan,B.B.Adeleke,Hydroquinone and heavy metal levels in cosmetics marketed in Nigeria, Trends Appl.Sci.Res.6(2011) 622-639

[3]. S.I Reed, Cosmetics and Your Health, U.S Department of Health and Human ervices, 2004.

[4]. N.Roa,S.Pathriba, Cosmetics and Personal Care products, IElsevier Inc.1998. pp,380-382.

[5]. Novak N and BieberT, The skin as a target for allergic diseases, Allergy,55(2),2008, 103-107.

[6]. Corazza M, Baldo F, PagnoniA,Miscioscia R and Virgili A, Measurement of nickel, cobalt and chromium in toy makeup by atomic absorption spectroscopy,ActaDermato Venereologica,89(2), 2009,130-133.

[7]. Al-Saleh I, Al-Enazi S and Shinwari N, Assessment of lead in cosmetic products, Regulatory Toxicol. and Pharmacol.,54 (2), 2009, 105-113.

[8]. Chauhan AS, Bhadauria R, Singh AK,Lodhi SS, Chaturvedi DK and Tomar VK, Determination of lead and cadmium in cosmetic products, J.Chem. and Pharmaceu. Res.,6, 2010,92-97.

[9]. Sainio EL, Jolanki R, Hakala E and Kanerva L, Metals and arsenic in eye shadows, Contact Dermatitis, 42 (1), 2001,5 10 .

[10]. Alissa EM and Ferns GA, Heavy metal poisoning and cardiovascular disease, J. Toxicol.,2011, 2011, 1-21.

[11]. US FDA.United States Food and Drug Authorities, 2002a. Title 21 - Food and Drugs. Chapter I - Food and Drug Administration, Department of Health and Human Services. Part 74 - Listing of Color Additives Subject to Certification/Office of Cosmetics and Colors. Sec. 74.1306 D\&C Red No. 6.

[12]. Code of Federal Regulations (2008) Title 21 (U.S. Government Printing Office, Washington, DC), Sections 73, 74, and 82

[13]. Campaign for Safe Cosmetics, A Poison Kiss: The Problem of Lead in Lipstick, 2007.

[14]. C.C. Wang, A.N. Masi, L. FernándezTalanta, 75 (2008), pp. 135-140.

[15]. M. Ahamed, K.J. SiddiquiClin. Nutr., 26 (2007), pp. 400-408.

[16]. Koller K, Brown T, Spurgeon A, Levy L (2004). Recent development in low level lead exposure and intellectual impairment in children. Environ. Health. Perspect .112:987-994.

[17]. Guy, R., Hostynek, J.J., Hinz, R.S. and Lorence, C.R., Metals and the Skin: Topical Effects and Systemic Absorption,1999.

[18]. C.Lid'en,L.Skare,B.Lind,G.Nise,andM.Vahter,"Assessment of skin exposure to nickel, chromium and cobalt by acid wipe sampling and ICP-MS," Contact Dermatitis, vol. 54, no. 5, pp. 233-238,2006.

[19]. N. H. Nielsen, A. Linneberg, T. Menn'e et al., "Incidence of allergiccontactsensitizationinDanishadultsbetween1990and 1998;theCopenhagenAllergyStudy,Denmark,"BritishJournal ofDermatology,vol.147,no.3,pp.487-492,2002

[20]. D.A.Basketter,G.Briatico-Vangosa,W.Kaestner,C.Lally,and

W.J.Bontinck,"Nickel,cobaltandchromiumconsumerproducts:aroleinallergiccontactdermatitis?"ContactDermatitis, vol.28,no.1,pp.15-25,1993.

[21]. OMNICTM Spectra Software, database of spectral data 
IOSR Journal of Applied Chemistry (IOSR-JAC) is UGC approved Journal with S1. No. 4031, Journal no. 44190 .

Roopa S Belurkar. "Analysis of Heavy Metals in Lipstick by the Various Physio-Chemical and I Instrumental Methods." IOSR Journal of Applied Chemistry (IOSR-JAC) 10.7 (2017): 01-06. 